\title{
NOTAS TEÓRICO-METODOLÓGICAS SOBRE RELAÇÕES ENTRE VIVÊNCIA E PRÁXIS: ANÁLISE DE PRÁTICA PEDAGÓGICA
}

\author{
OLINDA MARIA NORONHA ${ }^{1}$ \\ "Toda práxis é atividade, mas nem toda atividade é práxis"
}

(VÁZQUEZ,1977, p. 185)

RESUMO: O objetivo deste artigo é contribuir para a reflexão teórico-metodológica sobre as relações entre vivência e práxis. A partir dessa discussão procura empreender uma análise de uma experiência pedagógica desenvolvida com professoras de educação infantil em que foi utilizada uma técnica conhecida como Psicodrama Pedagógico. Essa experiência foi realizada por uma professora com quem partilhei o trabalho e as discussões sobre a validade de tal técnica no processo de construção do conhecimento da realidade objetiva. $O$ artigo se desenvolve objetivando explicitar os desafios e as dificuldades de se compreender e superar a perspectiva reducionista, fragmentária e pragmática que o campo educativo tem enfrentado atualmente, principalmente com o advento da atitude epistemológica difundida pela agenda pós-moderna.

Palavras-chave: Vivência. Práxis. Conhecimento. Pedagogia. THEORETICAL-METHODOLOGICAL NOTES ON THE RELATIONS BETWEEN
EXPERIENCE AND PRAXIS: ANALYSIS OF PEDAGOGICAL PRACTICE

ABSTRACT: The purpose of this article is to contribute to theoretical methodological reflection on the relationship between experience and praxis. From this discussion seeks to undertake an analysis of a pedagogical experience developed with teachers of early childhood education in which a technique known as Pedagogical Psychodrama was used. This experience was carried out by a teacher with whom I shared the work and the discussions about the validity of such technique in the construction of the knowledge of the objective reality. The article develops to explain the challenges and difficulties of understanding and overcoming the reductionist, fragmentary and pragmatic perspective that the education field has faced today with the advent of the epistemological attitude diffused by the postmodern agenda.

Keywords: Experience. Praxis. Knowledge. Pedagogies.

1 Livre-docente em História da Educação - UNICAMP/SP. 


\section{NOTAS TEÓRICO-METODOLÓGICAS SOBRE RELACIONES ENTRE VIVENCIA Y PRAXIS: ANÁLISIS DE PRÁCTICA PEDAGÓGICA}

RESUMEN: El objetivo de este artículo es contribuir a la reflexión teórica metodológica acerca de las relaciones entre vivencia y praxis. A partir de esa discusión procura emprender un análisis de una experiencia pedagógica desarrollada con profesoras de educación infantil en la que fue utilizada una técnica conocida como Psicodrama Pedagógico. Esa experiencia fue realizada por una profesora con quien compartía el trabajo y las discusiones acerca de la validez de tal técnica en la construcción del conocimiento de la realidad objetiva. El artículo se desarrolla con el objetivo de explicitar los desafíos y las dificultades de comprender y superar la perspectiva reduccionista, fragmentaria y pragmática que el campo educativo enfrenta actualmente con el advenimiento de la actitud epistemológica difundida por la agenda postmoderna.

Palabras clave: Vivencia. Praxis. Conocimiento. Pedagogía.

\section{Introduzindo a reflexão sobre o tema do estudo}

A busca do diálogo entre as diversas abordagens teórico-metodológicas com o propósito de compreensão da realidade parece ser, em princípio, uma postura das mais férteis e avançadas tanto para a ciência em geral como para a investigação em educação de modo particular. No entanto, é preciso tomar alguns cuidados para não se incorrer no equívoco sedutor da argumentação pósmoderna que entende a proposta da interlocução entre as áreas do conhecimento tendo como pressuposto a dissolução das suas fronteiras.

Edgar Morin tem sido, entre outros, um dos teóricos defensores dessa atitude pós-moderna. De acordo com uma de suas reflexões sobre os problemas fundamentais que precisam ser enfrentados para se ensinar neste século esse autor afirma que: “[...] a supremacia do conhecimento fragmentado de acordo com as disciplinas impede frequentemente de operar o vínculo entre as partes e a totalidade" (MORIN, 2002, p. 14).

A atitude enfática de busca de integração dos vários estudos, buscando o vínculo proposto por Morin e outros propagadores da ideologia pós-moderna, à primeira vista pode parecer apenas uma atitude inovadora que visaria superar a fragmentação e o isolamento das reflexões no âmbito das disciplinas possibilitando, desta maneira, um suposto avanço em direção a uma abordagem metodológica da chamada compreensão pluridimensional da realidade. No entanto, os fundamentos que embasam esse tipo de reflexão estão situados no ambiente difundido pela ideologia pós-moderna que tem caracterizado a sociedade contemporânea.

A principal crítica feita pelos pós-modernos à maneira como as disciplinas estão organizadas 
é a de que o mundo atual é complexo e de que, portanto, para se chegar a sua compreensão é preciso superar os reducionismos que as disciplinas impõem ao saber e interligar os saberes pelas teias ou redes de conhecimento. Desse modo, os defensores da pós-modernidade alegam que os limites ou as fronteiras disciplinares rígidas das ciências, tal como se encontram organizadas, expressam a racionalidade capitalista da divisão técnica do trabalho e, portanto, precisam ser superadas. Essa superação se daria por meio de uma atitude metodológica que integrasse de modo subjetivo e global os saberes. A justificativa para a adoção dessa atitude é a de que as pessoas vivem hoje em comunidades que são complexas, multiculturais, praticando múltiplas formas de diversidade e de identidades e, que só por meio das teias e redes de conhecimento tornar-se-ia possível chegar à compreensão do mundo.

Como constata Wood (1999), ao analisar e criticar os fundamentos da agenda pós-moderna,

Há ainda outro aspecto muito curioso do pós-modernismo corrente, um paradoxo especialmente notável. Por um lado, a negação da história em que se baseia está ligada a uma espécie de pessimismo político. Uma vez que não há sistemas ou história suscetíveis à análise causal, não podemos chegar à origem de muitos poderes que nos oprimem. Nem tampouco, certamente, aspirar a algum tipo de oposição unificada, de emancipação humana geral, ou mesmo a uma contestação geral do capitalismo, como os socialistas costumavam acreditar; o máximo que podemos esperar é um bom número de resistências particulares e separadas (p. 15).

A argumentação pós-moderna precisa ser compreendida e refutada a partir da questão epistemológica de que a perspectiva conceitual da "complexidade" representa uma atitude anticientífica que tende ao irracionalismo e à dissolução dos campos do conhecimento anulando com isto as suas especificidades. Algumas consequências dessa posição é a mistura da vivência com a práxis, das múltiplas culturas e linguagens, do conhecimento universal com o cotidiano, do conceito de comunidade substituindo o conceito de sociedade (não existe mais país e sim grupos de autoajuda, de ajuda mútua, cooperativas autossustentáveis, empreendedorismo individual, estilos de vida e outras expressões do gênero).

No âmbito da educação, essa ideologia defende que o aluno não necessita adquirir conhecimento e sim "aprender a aprender". Precisa estar preparado - adquirir as competências - para resolver problemas imediatos e formular soluções no interior de uma cidadania participativa, por meio de uma atitude crítica positiva e pragmática visando à produtividade do mundo capitalista. Um dos argumentos centrais dos pós-modernos é o de que as novas tecnologias de produção e de gestão 
exigem que os compartimentos isolados das disciplinas sejam substituídos por uma forma de compreensão globalizada e integrada pelas teias. E de que a ciência, tal como está estruturada, não só não consegue atingir como inviabiliza os conteúdos de aprendizagem que sejam funcionais e ajudem os alunos a resolver seus problemas imediatos. A perspectiva de diálogo entre campos do saber, implícita nas reflexões que integram o esforço coletivo de pensar a educação não deve ser confundida, portanto, com a posição pós-moderna de dissolução das fronteiras do conhecimento uma vez que inviabiliza a dialética singular-particular-geral.

\title{
Construindo os fundamentos teóricos-metodológicos das relações dialéticas entre vivência e práxis
}

O presente estudo procura trazer uma contribuição à compreensão das relações singularparticular-universal na medida em que procura entender as relações dialéticas entre vivência e práxis. O pressuposto teórico-metodológico que fundamenta a análise é o de que para se atingir a essência da realidade histórica é preciso partir do movimento que busca compreender o singular e o particular como expressão do universal em um permanente movimento histórico-dialético - que constitui o modo de produção material da sociedade - e, por meio deste movimento, poder contribuir para a compreensão das forças históricas que estão presentes nestas relações. Mas essa contribuição somente se torna possível se o dilema apontado por Frigotto (2001) for enfrentado adequadamente pelos pesquisadores. Esse dilema é assim formulado por Frigotto.

\begin{abstract}
O dilema do presente para aqueles que trabalham com a teoria marxista passa a ser: ou ela se satura de historicidade e se mantém robusta como instrumental mais adequado para uma compreensão e crítica da sociabilidade e do aprofundamento das contradições do capital e, como tal, uma força material na construção de relações sociais alternativas, ou se constituirá apenas numa formulação discursiva impotente (FRIGOTTO, 2001, p. 31).
\end{abstract}

Com o propósito de situar a questão que fundamenta essas reflexões de ordem teórica e metodológica, cabe dizer inicialmente que o problema das relações entre vivência e práxis tem seus fundamentos tanto na questão filosófica e histórica que procura responder - quem é o homem, o que é a sociedade e como ela é produzida -, quanto na questão metodológica da construção do conhecimento - relações entre teoria-prática, sujeito-objeto, particular-universal, cotidiano-história.

As relações entre vivência e práxis se referem, antes de mais nada, ao problema da experiência sensível, da necessidade desta como fonte e limite da práxis humana, da produção de 
objetos pelo homem e da possibilidade da construção do conhecimento objetivo. Recorrendo-se às ricas reflexões que Vázquez (1977) desenvolve em "Filosofia da Práxis", estudo que constitui uma referência metodológica para o tratamento dessa questão, é possível encontrar o emprego do termo "práxis" desde sua etimologia grega.

Práxis, em grego antigo, significa ação para levar a cabo algo, mas uma ação que tem um fim em si mesma e que não cria ou produz um objeto alheio ao agente ou a sua atividade. Nesse sentido, a ação moral - da mesma maneira que qualquer tipo de ação que não engendre nada fora de si mesma - é, como diz Aristóteles, práxis: pela mesma razão, a atividade do artesão que produz algo que chega a existir fora do agente de seus atos não é práxis. A esse tipo de ação que cria um objeto exterior ao sujeito e a seus atos se chama em grego poiésis, que significa literalmente produção ou fabricação, ou seja, ato de produzir ou fabricar algo" (VÁZQUEZ, 1977, p. 4-5).

Vázquez conclui a partir dessa constatação que o trabalho do artesão é uma atividade poética, e não prática. O objetivo de Vázquez, contudo, não é o de ficar fiel ao conceito grego de práxis, mas trabalhar com ele a partir de seu objetivo primordial que é o de designar a atividade humana que produz objetos, sem que essa atividade seja concebida com o caráter estritamente utilitário. Por isso entende práxis como a categoria central da filosofia que se concebe ela mesma não só como interpretação do mundo, mas também como guia de sua transformação. Esse é o conceito central que busca orientar as reflexões deste estudo.

Com base em uma perspectiva que separa teoria e práxis - próprias do materialismo vulgar e da visão burguesa de mundo -, a relação com a experiência pode limitar a práxis aos estreitos limites do materialismo tradicional e do pragmatismo (aversão à teoria e à razão utilitária). No entanto, a compreensão da práxis dentro de uma relação abstrata com a teoria pode reduzi-la aos limites do idealismo e da abstração (razão pura).

Como superar essa polarização e conduzir a compreensão da práxis para o plano de uma atividade humana essencialmente transformadora constitui um problema tanto de ordem filosófica quanto metodológica. Nas teses sobre Feuerbach, Marx (MARX; ENGELS, 1959a) apresentam-se as falhas do materialismo tradicional que considerava a realidade como algo oposto ao homem e não como objeto da ação deste sobre a natureza. Nesse sentido, Marx observa que o conhecimento só é conhecimento de uma realidade criada pelo homem na história e que este, ao criar os objetos necessários a sua sobrevivência, transforma a natureza, se transforma e transforma os outros homens. Dessa forma, a práxis tanto pode ser o fundamento quanto o limite do conhecimento, dependendo do 
modo como o homem se relaciona com a realidade. Assim, a práxis humana, dependendo da sua qualidade, pode ser utilitária ou transformadora.

Sobre essa questão Kosik (1976) considera, em seu emblemático livro "Dialética do Concreto", que o fato de o pensamento dialético fazer uma distinção entre representação e conceito da coisa não significa que se deva distinguir duas formas e dois graus de conhecimento da realidade, mas duas qualidades da práxis humana.

O que Kosik quer enfatizar é que, do ponto de vista dialético

[...] a atitude primordial e imediata do homem, em face da realidade, não é a de um abstrato sujeito cognoscente, de uma mente pensante que examina a realidade especulativamente, porém, a de um ser que age objetiva e praticamente, de um indivíduo histórico que exerce a sua atividade prática no trato com a natureza e com os outros homens, tendo em vista a consecução dos próprios fins e interesses, dentro de um determinado conjunto de relações sociais (KOSIK, 1976, p. 9).

No entanto, essa atitude primordial de um ser que age de modo prático-sensível na realidade não pode ser identificada ou confundida com a compreensão desta mesma realidade. Ou seja, a ação imediata que integra o campo da vivência humana corresponde à práxis imediata cujo elemento definidor é o senso comum. Esse momento da práxis não permite ao homem chegar às determinações de sua atividade objetiva sobre o mundo. Sua ação prática, utilitária e fragmentada limita o homem à ação para satisfazer suas necessidades de orientação e de ajustes ao mundo, mas não o conduz à busca das leis que regem sua ação e a dos outros homens, ou seja, a essência, as relações e o conceito a elas correspondente. A qualidade da práxis no mundo da vivência cotidiana, que corresponde à satisfação das necessidades imediatas, constitui para Kosik o mundo da forma fenomênica, que é a forma da práxis unilateral, limitada e fragmentária. Assim ele se expressa sobre essa questão: “[...] historicamente determinada e unilateral, é a práxis fragmentária dos indivíduos, baseada na divisão do trabalho, na divisão da sociedade em classes e na hierarquia de posições sociais que sobre ela se ergue" (KOSIK, 1976, p. 10).

No interior dessa práxis fragmentada e superficial, o homem parece se mover de maneira utilitária e naturalizada em seu cotidiano, ao mesmo tempo em que absorve essa atmosfera ideologizada com seu caráter utilitário e imediato, sem penetrar nas determinações de seu agir espontâneo. A realidade em que o homem está mergulhado aparece de forma autônoma sem relações com a totalidade das determinações históricas do vivido. Kosik denomina essa atmosfera espontânea, 
utilitária e ideologizada da vida cotidiana de "mundo da pseudoconcreticidade" ou de "práxis fetichizada", que consiste no "pensamento comum", na "consciência ingênua", no "mundo dos fenômenos externos".

Para esclarecer as concepções fundamentais que estão na base da constituição do mundo da aparência ou realidade fetichizada, Kosik retoma Marx e considera que

[...] o mundo que se manifesta ao homem na práxis fetichizada, no tráfico e na manipulação não é o mundo real, embora tenha a "consistência" e a "validez" do mundo real: é o "mundo da aparência" [...] o impulso espontâneo da práxis e do pensamento para isolar os fenômenos, para cindir a realidade no que é essencial e no que é secundário, vem sempre acompanhado de uma igualmente espontânea percepção do todo, na qual e da qual são isolados alguns aspectos, embora para a consciência ingénua esta percepção seja muito menos evidente e muitas vezes imatura" (KOSIK, 1976 p. 15 - grifos nossos).

Aquilo que o homem observa de modo imediato e natural no mundo cotidiano - o fenômeno - revela e esconde a sua essência, a sua estrutura - ou suas determinações. Para se atingir a essência, a compreensão do fenômeno, é necessário o esforço da investigação que decompõe a estrutura deste fenômeno em partes. Marx, em sua discussão sobre o método histórico de construção do conhecimento, torna evidente a distinção entre mundo da essência e mundo da aparência, demonstrando que o conceito de realidade é muito mais abrangente do que aquilo que se manifesta no mundo sensível.

Como afirma Marx, “[...] aliás, toda ciência seria supérflua se houvesse coincidência imediata entre a aparência e a essência das coisas" (MARX, 2008, p. 1080). Dessa maneira, a compreensão do fenômeno implica no esforço metodológico de conhecimento de sua estrutura, e o materialismo histórico-dialético constitui o pensamento crítico que busca esta compreensão. Kosik (1976, p. 14-20) amplia a discussão metodológica iniciada por Marx, considerando a esse respeito que

[...] "o conhecimento é que é a própria dialética em uma de suas formas, o conhecimento é a decomposição do todo [...] o conhecimento se realiza como separação de fenômeno e essência [...] a representação da coisa não constitui uma qualidade natural da coisa e da realidade: é a projeção, na consciência do sujeito, de determinadas condições históricas petrificadas [...] na destruição materialista da pseudoconcreticidade. A liberalização do "sujeito" (vale dizer, a visão concreta da realidade, ao invés da "intuição fetichista") coincide com a liberalização do "objeto" (criação do ambiente humano como fato humano dotado de condições de transparente racionalidade) posto que 
a realidade social dos homens se cria como união dialética de sujeito e objeto (grifos nossos).

É importante, por conseguinte, que se resgate o caráter relacional do processo de construção do conhecimento. Isso significa considerar que há um sujeito informado historicamente, que se relaciona com o objeto, construindo-o e sendo ao mesmo tempo construído neste processo. A controvérsia sobre a dualidade sujeito-objeto tem de ser superada tanto no âmbito da teoria quanto no da prática, sob pena de não se conseguir avançar nem do ponto de vista do conhecimento, nem da contribuição que este pode dar ao movimento de construção da identidade de classe dos segmentos chamados "subalternos".

A relação dialética sujeito-objeto tem como pressuposto que a teoria se altera no trânsito com a realidade. Assim como ela também se altera com a teoria. A produção do conhecimento não pode ser diluída na necessidade histórica de intervenção imediata no processo social para transformálo. Torna-se necessário discernir o campo próprio da produção do conhecimento do nível de intervenção no processo para transformá-lo. Em outras palavras, é preciso transformar a "verdade prática" - mundo da pseudoconcreticidade - em "verdade teórica" - mundo do conhecimento - para que a primeira ganhe um conteúdo revolucionário (NORONHA, 1991, 2002, 2006).

A atitude metodológica que tem a intenção de transformar a verdade prática em verdade teórica precisa se constituir em um esforço de caráter permanente pois, como observa Lefebvre (1973),

[...] a sociabilidade capitalista constrói uma realidade urbana fragmentada, um espaço controlado e nesse espaço, metodológica (e epistemologicamente) se instala o conflito entre o "vivido sem conceito" e o "conceito sem vida". Uns dispensam-se de pensar e outros dispensam-se de viver (LEFEBVRE, 1973, p. 20 - grifos nossos).

O vivido sem conceito constitui o mundo da vivência, do pragmatismo e o conceito sem vida, o mundo da abstração, do idealismo. A superação desse conflito se torna possível com a compreensão da essência do modo como a sociabilidade capitalista se estrutura e constrói o mundo fetichizado das relações de trabalho no interior das relações sociais de produção em toda a sociedade.

É, portanto, em todo o espaço ocupado pelo neocapitalismo setorizado, reduzido a um meio aparentemente homogêneo, mas profundamente fragmentado, que deve incidir a atitude metodológica fundamental de superação do mundo fenomênico da aparência da coisa para atingir sua 
estrutura. É essencial que o pesquisador não assuma os "pedaços", os "fragmentos" independentes como objeto de pesquisa, mas trabalhe com a categoria totalidade, desenvolvendo o esforço teóricometodológico de articulação entre cotidiano e História.

É difícil ao pesquisador, quando trabalha com objetos e sujeitos particulares, evitar a armadilha de se perder no cotidiano, de ficar no nível da aparência do fenômeno. Se, de um lado, a vida cotidiana constitui a premissa básica para se fazer História - para viver, é preciso comer, beber, morar, vestir etc. -, que representa o primeiro fato histórico que é a produção dos meios materiais para a subsistência nas relações que se estabelecem com a natureza e com os outros homens; de outro, constitui a possibilidade de transformação da realidade, pois, tão logo as primeiras necessidades estejam satisfeitas nas relações que se estabelecem entre os homens com a natureza mediada por outros homens, novas necessidades serão criadas.

Sobre essa questão Marx e Engels consideram na Ideologia Alemã, que "a produção da vida [...] se manifesta imediatamente como uma dupla relação - de uma parte, como uma relação natural, e de outra como uma relação social" (MARX; ENGELS, 1976, p. 18). Contudo, se o homem fica prisioneiro da ação instrumental de somente satisfazer as suas necessidades imediatas, tende a não conseguir perceber a essência de sua ação. Desse modo, a práxis é a fonte e o limite do conhecimento. Kosik acrescenta a essa reflexão o papel criador da atividade humana: "[...] o homem só conhece a realidade na medida em que ele cria a realidade humana e se comporta antes de tudo como ser prático" (KOSIK,1976. p. 22).

No entanto, para que esse conhecimento da realidade ocorra, o homem precisa buscar a essência das coisas, pois esta não se manifesta de modo direto. Somente pela investigação criteriosa, buscando não a essência última dos fenômenos - como pensavam os clássicos -, mas suas determinações estruturais históricas se tornam possíveis à superação do mundo da vivência e a passagem deste para o da práxis transformadora. A ruptura com a compreensão ingênua da realidade exige por parte do homem uma atitude constante de busca de articulação metodológica entre o singular, o particular e o universal, entre o mundo da existência fenomênica e o mundo da essência estrutural das coisas. Como esse caminho e essa atitude metodológica são difíceis, Kosik observa que diante dessas dificuldades o apelo ao misticismo representaria uma forma de burlar as dificuldades inerentes ao exercício metodológico de passar da aparência à essência do fenômeno. Ela constitui a questão fundamental do processo de construção do conhecimento. Kosik segue suas reflexões ressaltando que, 
[...] a humanidade tenta poupar-se o trabalho de conhecer [...] e procura observar diretamente a essência das coisas (o misticismo é justamente a impaciência do homem em conhecer a verdade). Com isso corre o perigo de perder-se ou de ficar no meio do caminho (KOSIK,1976, p. 21).

Outra maneira de se desviar da tarefa de conhecer as determinações estruturais da realidade expressa na vivência imediata pode ser caracterizada pela ação simplificadora da atividade de conhecer, recorrendo-se a estratégias mais prazerosas de ensino e de pesquisa, que tendem a supervalorizar o lúdico em detrimento da investigação rigorosa, desprezando-se a atitude metodológica de articulação entre o singular, o particular e o universal e o uso de categorias de análise como totalidade, contradição, movimento, mediação. A ação humana tende a se desenrolar no plano da superfície das coisas, impulsos de ação e reação, e parece ser mais significativo ser "feliz" com o imediato e com o sensível que a percepção fenomênica oferece, do que "sofrer" procurando as determinações do sensível e da felicidade.

Guardadas as devidas proporções, pode-se associar essa atitude de 'felicidade' imediata proporcionada pela abordagem da realidade que fica no nível da aparência do fenômeno com 'anatomia do riso' a partir da análise desenvolvida por Hobbes. Para esse filósofo, "[...] rir em demasia é sinal de pusilanimidade, pois ri muito quem tem poucas habilidades [...] o riso para Hobbes seria uma estratégia para lidar com nossos sentimentos de inadequação e de insegurança" (HOBBES apud MATTOS, 2003, p. 3)

Essas atitudes acima mencionadas podem resolver um problema existencial imediato, que é o de se adequar ou de se ajustar à realidade da maneira menos traumática possível, por meio de técnicas que tendem a tornar "mais fácil" ou "mais agradável" a ação de estar no mundo bem como a atividade de compreender o mundo, todavia não mudam a realidade que está causando a insegurança e a ansiedade diante do objeto a ser compreendido. A sensação de impotência diante da realidade provém, sobretudo, da incompreensão e do desconhecimento das leis que regem os fenômenos e do seu sentido objetivo. Por isso a atitude de "fuga" diante das dificuldades de compreensão e de explicação do real não pode ser confundida com uma postura revolucionária. Assim se refere Kosik a respeito desse problema:

[...] na modificação existencial o sujeito não muda o mundo, mas muda a própria posição diante do mundo. A modificação existencial não é uma transformação revolucionária do mundo; é o drama individual de cada um no mundo. Na modificação existencial o indivíduo se liberta de uma existência 
que não lhe pertence e se decide por uma existência autêntica. [...] fazendo isto, ele desvaloriza a cotidianidade com sua alienação, se eleva acima dela, mas ao mesmo tempo nega, com isso, também o sentido da própria ação (KOSIK, 1976, p. 79).

No entanto, apesar dessas dificuldades que fazem parte do mundo das relações fetichizadas, em que o homem vive e se relaciona, é só a partir de sua atividade prática que ele consegue se apropriar do mundo na forma de "coisas para si", porém dentro dos limites de uma atitude utilitária. Para ultrapassar o mundo da realidade imediata e utilitária em que ele vive, e chegar à essência das coisas, precisa, contudo, desenvolver uma atividade de investigação que conduza à estrutura das coisas, de suas determinações históricas, que levaria ao conhecimento da "coisa em si". "O homem só conhece a realidade na medida em que ele cria a realidade humana e se comporta antes de tudo como ser prático" (KOSIK, 1976, p. 22).

No entanto, o homem não pode ser presa deste mundo prático que ele cria para viver, acreditando que é capaz de conhecê-lo de forma espontânea e natural. Além do sentido natural que ele atribui ao mundo, proveniente das sensações, é preciso compreender o sentido objetivo das coisas que ele cria. É importante lembrar que os "sentidos" por meio dos quais o homem cria, recria, se relaciona, descobre e atribui sentidos às coisas são também um produto histórico-social. É nesse âmbito que deve ser compreendida a reflexão de Marx, sobre o caráter das relações de apropriação que o homem realiza dentro da lógica capitalista.

A propriedade privada nos tornou tão estúpidos e unilaterais que um objeto somente é nosso quando o temos, quando existe para nós enquanto capital ou quando é imediatamente possuído, comido, bebido, vestido, habitado; em suma, utilizado por nós [...] em lugar de todos os sentidos físicos e espirituais apareceu, assim, o simples estranhamento de todos estes sentidos, o sentido de ter. No entanto, como observa Marx a [...] formação dos cinco sentidos é um trabalho de toda a História universal até nossos dias. O sentido que é presa da grosseira necessidade prática tem somente um sentido limitado (MARX; ENGELS, 1959b, p. 33).

Desse modo, para que o homem compreenda o sentido objetivo das coisas que ele cria, é preciso que seja superado o âmbito da necessidade vulgar, da posse e do uso imediato e fragmentado e seja buscado o núcleo das determinações históricas dessas coisas criadas. Se o homem ficar retido na forma fenomênica do sensível, da vivência cotidiana, da opinião, das experiências imediatas observáveis, não conseguirá atingir o sentido objetivo das coisas. Para que seja possível sair do mundo da vivência, da imediaticidade, da experiência, do sensível, da aparência do fenômeno, é preciso 
realizar o movimento histórico-dialético que vai da parte para o todo e do todo para a parte - dialética particular-geral. Essa abordagem metodológica se encontra nas reflexões de Kosik ao considerar que

O progresso da abstratividade à concentricidade é, por conseguinte, em geral movimento da parte para o todo e do todo para a parte; do fenômeno para a essência e da essência para o fenômeno; da totalidade para a contradição e da contradição para a totalidade; do objeto para o sujeito e do sujeito para o objeto. [...] $\mathrm{O}$ processo do pensamento não se limita a transformar o todo caótico das representações no todo transparente dos conceitos; no curso do processo o próprio todo é concomitantemente delineado, determinado e compreendido (KOSIK, 1976, p. 30).

Essa reflexão de Kosik constitui uma diretriz metodológica significativa para a compreensão da realidade e para a construção do conhecimento, pois embora o todo seja perceptível ao homem na sua realidade prática imediata, não é imediatamente cognoscível. Apenas mediante o esforço teóricometodológico de investigação, que inclui a apropriação dos detalhes históricos da realidade, e de uma análise cuidadosa de como os elementos da realidade se estruturam e se articulam historicamente expressando as circunstâncias daquele momento histórico, é que se torna possível atingir a essência do fenômeno vivido. Se esse processo deixa de ocorrer, fica-se no âmbito da contemplação, da especulação abstrata e vazia, ou, o que é pior, perde-se no meio do caminho e não se chega à compreensão e à explicitação do fenômeno (método de exposição). É com esse sentido que Marx distingue formalmente o método de investigação do método de exposição.

É mister, sem dúvida, distinguir, formalmente, o método de exposição e o método de pesquisa. A investigação tem de apoderar-se da matéria em seus pormenores, de analisar suas diferentes formas de desenvolvimento, e de perquirir a conexão íntima que há entre elas. Só depois de concluído esse trabalho é que se pode descrever, adequadamente, o movimento real. Se isto se consegue, ficará espelhada, no plano ideal, a vida da realidade pesquisada, o que pode dar a impressão de uma construção a priori (MARX, 2008, p. 16).

O método de exposição não consiste, portanto, em uma análise evolucionista da realidade, ou em uma mistura eclética de posições teóricas sobre ela, muito menos em uma combinação mais ou menos ordenada de assuntos com o objetivo de supostamente "dar conta" da complexidade do real. Por trabalhar com a totalidade histórica e, nesse processo, desenvolver de modo permanente o movimento entre o particular e o geral, esse método não pode ser confundido com a perspectiva da totalidade holística. Nesse contexto Kosik destaca que

A falsa totalização e sintetização manifesta-se no método do princípio 
abstrato que despreza a riqueza do real, isto é, a sua contraditoriedade e multiplicidade de significado, para levar em conta apenas aqueles fatos que estão de acordo com o princípio abstrato. O princípio abstrato, erigido em totalidade, totalidade vazia, que trata riqueza do real como resíduo irracional e incompreensível. [...] o ponto de vista da totalidade concreta nada tem de comum com a totalidade holística, organicista ou neorromântica, que hipostasia o todo antes das partes e efetua a mitologização do todo. A dialética não pode entender a totalidade como um todo já feito e formalizado, que determina as partes, porquanto à própria determinação da totalidade pertencem a gênese e o desenvolvimento da totalidade, o que, de um pontode vista metodológico, comporta a indagação de como nasce a totalidade e quais são as fontes internas do seu desenvolvimento e movimento. A totalidade não é um todo já pronto que se recheia com um conteúdo, com as qualidades das partes (KOSIK, 1976, p. 49).

O processo pelo qual se torna possível atingir a totalidade histórica e a essência objetiva do fenômeno supõe, desta maneira, a destruição daquilo que Kosik denomina de "mundo da pseudoconcreticidade", que é o mundo da aparência, da vivência cotidiana, e da falsa consciência, da falsa objetividade.

\section{Retomando alguns princípios metodológicos para a investigação de uma experiência pedagógica na busca das relações entre vivência e práxis}

A partir dessas anotações de caráter teórico-metodológico, pretende-se passar ao exame das práticas de uma experiência pedagógica conhecida como "Psicodrama Pedagógico" - ver em anexo breve descrição desta técnica - tendo como ponto de partida as vivências de alguns alunos e professores que praticaram esta atividade em ambiente escolar visando o desenvolvimento de processos de ensino-aprendizagem. O material empírico utilizado para análise das relações entre vivência e práxis neste estudo, vieram, portanto, dos relatos desses alunos e professores desse curso de Psicodrama Pedagógico, ministrado por uma docente de ensino superior em uma escola de educação infantil do Estado de São Paulo. Para o desenvolvimento da análise se retoma aqui o pressuposto de que para que o conhecimento da realidade ocorra, a vivência precisa percorrer o caminho metodológico da superação da sua autonomia em relação aos processos históricos que o produzem, podendo, então, aspirar a trilhar as sendas de uma práxis transformadora.

Como analisar metodologicamente a práxis do professor em seu cotidiano com base nessas considerações? Como uma práxis fragmentária circunscrita no plano das sensações, da simples vivência, poderia, apesar desta limitação inicial vir a consistir também em fonte ou possibilidade de 
superação do conhecimento fragmentário do mundo sensível e produzir contraditoriamente, ações que conduzam à transformação da realidade? Com o propósito de encontrar algumas diretrizes para esses questionamentos, é apresentada a seguir uma síntese dos pressupostos teórico-metodológicos que foram desenvolvidos até o presente momento.

Em primeiro lugar, é importante que seja recuperado o pressuposto da análise marxista trabalhado por Kosik de que a compreensão da realidade objetiva não se dá de forma espontânea, imediata, ou automática e de que, portanto, o conhecimento é a própria dialética em uma de suas formas, é a decomposição do todo. Supõe dessa maneira o exercício constante de aprendizagem e prática da destruição da aparência das coisas, para atingir a sua essência. É preciso compreender a realidade para transformá-la.

Depreende-se, desse modo, que se o conhecimento da realidade é condição para a sua transformação, é necessário que ele seja desenvolvido enquanto processo de superação do mundo da aparência e das sensações imediatas. Somente assim se torna possível o rompimento com a práxis fragmentária e imediata em que os sujeitos se encontram. O mundo da pseudoconcreticidade é fruto da divisão do trabalho, da sociedade de classes e da hierarquia social que se estrutura a partir desse tipo de organização social.

Em segundo lugar, é importante ressaltar que a aprendizagem do processo de construção do conhecimento objetivo tem de ser exercitada desde a infância, como forma de aprendizagem que levem à aquisição dos instrumentos fundamentais de compreensão da realidade a partir de suas determinações essenciais, para que seja possível o desenvolvimento da ação transformadora no mundo. Esse conhecimento, por sua vez, não pode ser reduzido ao chavão já desgastado pelo uso metodológico inadequado de "acesso ao saber socialmente acumulado". Pois esse só ganha sentido histórico-revolucionário se vitalizado na e pela práxis em que alunos e professores são sujeitos no/do processo de transmissão-assimilação-superação do saber socialmente elaborado pelo conjunto dos homens em sua história concreta. O saber é, dessa forma, compreendido não como algo monolítico e fossilizado, pronto e acabado, que corresponderia à reedição da posição idealista, que postula que são as ideias que fundam a transformação do mundo, independentemente da relação teoria-prática. Retoma-se aqui o princípio indicado anteriormente por Frigotto (2001) de que é preciso "saturar de historicidade a teoria marxista".

Em terceiro lugar, a partir desse entendimento, recupera-se o princípio de que o 
conhecimento é construído no interior de uma pedagogia, a pedagogia da práxis. O significado dessa diretriz tem um grande alcance metodológico para a educação, pois implica que a prática é o fundamento e o limite do conhecimento e do objeto humanizado que, como produto da ação, é objeto do conhecimento. Como a prática não fala nem revela nada por si mesma no âmbito das evidências, tem, portanto, de ser interpretada e analisada, já que seu sentido essencial não é possível de ser captado de forma direta, pela observação imediata.

Em quarto lugar, reafirma-se que as relações que se estabelecem entre professor e alunos precisam ser entendidas tendo como elemento fundante a consideração de ambos como sujeitos históricos, que ao mesmo tempo em que são modicados pelas circunstâncias são capazes de nelas atuar, modificando-as. Dessa forma, refuta-se a afirmação de que o princípio do desenvolvimento da humanidade se encarna numa parte da sociedade, no caso, o professor. No entanto, é preciso ter cuidado para não cair na armadilha vulgarizada pelo senso comum de que já que todos são educadores ninguém educa ninguém, induzindo a um espontaneísmo grosseiro.

Em quinto lugar, indica-se como fundamental a ação do professor como mediador de uma práxis mais elaborada do ponto de vista do conhecimento, para que a práxis revolucionária possa ser desenvolvida nas relações que se estabelecem no processo pedagógico. As relações que se estabelecem no processo de construção do conhecimento não podem ser confundidas com "interacionismo", ou somente com um relacionamento cheio de prazer e de camaradagem, ficando reduzidas somente a esse aspecto superficial, secundarizando o fundamental, que é a compreensão da essência objetiva da realidade. As relações que são construídas no processo pedagógico devem evitar o ato de atribuir "supremacia" ao papel do professor, e "autonomia" à ação do aluno (identificado ideologicamente como um indivíduo "livre" no mercado para adquirir os saberes necessários à sua afirmação no mundo competitivo em que vive).

A sociedade, nessa perspectiva acima mencionada, coincide com a postura pós-moderna tendendo a ser reduzida a um agregado de identidades individuais, e as distinções sociais aparecem não como resultado da organização da sociedade em classes, mas como opções pessoais ou estilo de vida. No entendimento de Stabile, "a consequência desse foco micropolítico é que a política de identidade passa a fundamentar-se sobre "estilo de vida", consumo etc., e o individualismo substitui a política de interesses comuns e de luta social coletiva" (STABILE, 1999, p. 151 - grifo da autora).

Em sexto lugar, a partir dessa constatação, depreende-se a necessidade de rompimento com 
a perspectiva atual difundida pelas concepções ideologizadas da "pós-modernidade", que tem como uma de suas manifestações na educação o construtivismo. Em linhas gerais, ele considera que o conhecimento é apenas instrumental, não podendo, portanto, ser construído historicamente, que não é possível atingir a verdade objetiva universal e que a inteligência é apenas um processo de adaptação. Como consequência, a categoria que define a educação é a assimilação, no nível do saber tácito.

A valorização do saber tácito - da experiência imediata ou da "reflexão na ação" -, contrapondo-se ao conhecimento explícito - elaborado ou escolar -, tende a desenvolver e difundir uma perspectiva naturalizada do homem e da sociedade, que pode ser traduzida no evolucionismo social e na ideia de ecossistema harmonioso, equilibrado e místico. A não articulação entre conhecimento tácito, da cotidianidade, e conhecimento elaborado, histórico, pode levar à polarização: pragmatismo de um lado e mistificação da História de outro. Nas observações de Kosik

Separada da História, a cotidianidade é esvaziada e reduzida a uma absurda imutabilidade; enquanto a História separada da cotidianidade se transforma em um colosso absurdamente impotente que irrompe como uma catástrofe sobre a cotidianidade, sem poder mudá-la, sem poder eliminar a banalidade nem Ihe dar um conteúdo (Kosik,1976, p. 73).

A superação dessa polarização se daria pela articulação entre cotidiano e História mediante a destruição do fetichismo tanto da cotidianidade quanto da História. É significativo ressaltar aqui as contribuições de Duarte (2003), no que se refere à demonstrar a emergência de uma epistemologia da prática articulada aos pressupostos neoliberais e pós-modernos que convergem para uma negação da perspectiva marxista de totalidade e para a desvalorização do conhecimento cientifico/teórico/acadêmico e escolar, junto à postura metodológica de que não há realidades objetivas possíveis de serem conhecidas.

Por fim, é importante considerar o professor e o aluno como sujeitos históricos submetidos a determinadas relações sociais. É necessário que essas relações históricas sejam compreendidas para que se possa agir tendo em vista o rompimento com a leitura ingênua da realidade, em que o mundo se manifesta no cotidiano como um mundo já pronto e imutável. Vivência ou práxis? É possível superar o âmbito do senso comum fragmentado?

Feitas essas considerações, será realizada a tentativa metodológica de análise de alguns relatos de experiências vivenciadas por professores e alunos em sala de aula por meio de técnicas dramáticas. O objetivo desta análise é observar a possibilidade ou não de existência de pontos de 
articulação entre a vivência do cotidiano em sala de aula e a construção de um processo de compreensão da realidade objetiva - práxis transformadora.

Observa-se inicialmente que em todos os relatos é desenvolvido um tipo de "procedimento padrão" em que são descritos o objetivo, a montagem do cenário e da cena, o aquecimento, a dramatização, o compartilhamento e uma espécie de síntese. É possível constatar que o ponto de partida de todos os trabalhos tomados como objeto de análise é a experiência sensível ou vivência no cotidiano dos alunos.

Importa saber nesse exame dos trabalhos qual foi o processo desenvolvido para que os alunos pudessem superar, ou não, o âmbito das opiniões, da aparência e das sensações espontâneas e atingir, ou não, a compreensão - conhecimento- da essência de sua prática histórica, fonte geradora dos problemas que estão sendo sentidos no cotidiano na forma fenomênica de "preocupação" e de "desconforto".

Os trabalhos foram organizados utilizando-se várias técnicas dramáticas, dentre as quais destacam-se algumas:

a) exemplificar e sentir, por meio da música, como o uso de drogas por adolescentes pode levar à marginalidade e à desestruturação familiar. O objetivo, nesse caso, era conseguir uma fixação mais eficaz do conteúdo trabalhado;

b) mediante uma vivência em sala da aula, sentir e concluir sobre a diferença de conviver com o professor robô e com o professor humano, na busca por uma escola ideal;

c) vivenciar um exercício filosófico prático e avaliar a compreensão dos conteúdos abordados, na forma de temas e questionamentos por meio de quatro personagens;

d) desenvolver uma experiência vivenciada, fazendo emergir espontaneamente componentes de realismo, de emotividade, de expressividade corporal e verbal, por meio de uma dinâmica envolvendo a construção do perfil do negociador, pela mediação de conflitos;

e) vivenciar um jornal vivo, tendo como finalidade fazer com que os alunos sentissem prazer em participar das aulas;

f) trabalhar uma vivência de dramatização desenvolvendo a espontaneidade e o aprimoramento das relações interpessoais; 
g) desenvolver uma vivência com psicodrama com o objetivo de refletir sobre a conceituação dos temas transversais contidos nos Parâmetros Curriculares Nacionais.

Uma vez identificados alguns dos temas centrais e objetivos dos trabalhos desenvolvidos, cabe ressaltar que as reflexões aqui empreendidas sobre o modo como os trabalhos foram conduzidos não têm nenhum caráter de desmerecimento quanto ao esforço de fazer avançar o trabalho pedagógico par a além de uma suposta prática autoritária. Vale lembrar que a contribuição dessa análise se situa especificamente no âmbito da discussão teórico-metodológica.

Pretende-se neste momento demonstrar que a alternância de técnicas didáticas ou de reformulação de alguns princípios pedagógicos, sem que estes sejam apreendidos nos limites das contradições sociais, que são possíveis de serem alcançadas somente mediante o rompimento com a aparência fetichizada das relações sociais, não são capazes por si só de contribuir para a construção do conhecimento objetivo da realidade. Defende-se aqui que somente por meio do conhecimento objetivo, e não das sensações imediatas da experiência, pode-se superar o risco recorrente de transformar a educação em uma panaceia supostamente "democratizada e emancipadora", com consequências educacionais, sociais e políticas que podem ser devastadoras para as camadas excluídas da sociedade.

Observa-se que apesar da diversidade temática desenvolvida nos trabalhos, em função das especificidades de cada disciplina, algumas questões são recorrentes nos relatos, tais como:

1. Ter como ponto de partida o senso comum da vivência cotidiana, bem como nele permanecer, apesar do desenvolvimento de técnicas pedagógicas de interação e de compartilhamento com os alunos;

2. a avaliação otimista da experiência vivida, apresentada pelos professores como altamente positiva pelos "atores" envolvidos (professores e alunos);

3. a avaliação se circunscreve somente no âmbito tecnicista (e neo-tecnicista) da eficiência ou ineficiência da técnica utilizada (inovadora, satisfatória, ferramenta eficiente, renovação pedagógica etc.), sem dar importância à compreensão objetiva do problema real que havia movido cada trabalho;

4. a impossibilidade metodológica de articulação entre teoria e prática e de estabelecimento de relações entre singular, particular e geral, entre sujeito e objeto, entre cotidiano e História; 
5. a tendência a buscar compreender as coisas de modo direto, sem a mediação da teoria;

6. a impossibilidade metodológica de construir o conhecimento, parecendo que a verdade está dada nas evidências ou manifestações do cotidiano, bastando "experimentá-la", "lidar com ela da melhor maneira possível", "controlar a angústia gerada pelo seu desconhecimento", "assimilar e fixar o conteúdo vivenciado" sem que seja desenvolvido um processo de compreensão e de explicação que conduzam a rupturas transformadoras que só o conhecimento objetivo da realidade vivenciada possibilita;

7. a supervalorização das emoções e dos sentimentos em detrimento de uma reflexão que conduza os envolvidos na experiência pedagógica em questão, a chegar às determinações, à raiz ou à essência dos problemas identificados e "dramatizados" em sala de aula;

8. a mistificação da atividade de investigação e de reflexão sobre a realidade diante da impaciência do homem em buscar conhecer as determinações históricas dos fenômenos que se apresentam como se fossem óbvios;

9. a consideração do homem no "estado natural" e não histórico, tendendo a reduzir o homem à subjetividade;

10. a maioria dos problemas vivenciados está no âmbito da "preocupação", e não da ação.

Apesar dessas limitações encontradas nos relatos analisados, pode-se entrever uma tênue possibilidade de superação do âmbito imediato, por meio de uma espécie de "indícios potenciais" de uma forma de compreensão qualitativamente diferenciada das simples sensações proporcionadas pela vivência do cotidiano. Essa frágil possibilidade pode ser observada naquilo que os relatos denominam de "síntese", e se refere a questões significativas, que infelizmente não foram detectadas pelo grupo, e muito menos trabalhadas pela técnica pedagógica utilizada. Estão apenas lá registradas, aguardando por uma relação pedagógica fundada em um processo que vise transformar o homem, da sua condição natural, em sujeito da sua história. E para que essa relação transformadora possa acontecer é preciso repensar também a educação do educador. Esses frágeis "indícios potenciais", que a miopia (teórica e metodológica) do professor não permite captar, podem ser constatadas nos fragmentos a seguir transcritos e analisados por este estudo.

O que dizem os principais fragmentos analisados:

- "Perceber na fala de todos os participantes o despertar de uma consciência centrada em 
valores éticos e humanos". Essa fala, se trabalhada de forma adequada, poderia resgatar o caráter de universalidade do sujeito, em contraposição ao conceito de identidades individuais.

- Mesmo dentro dos limites de uma proposta de escola ideal, surgiu a representação de "uma escola onde todos eram solidários, não havia violência nem preconceitos", expressando a busca de valores universais, o que poderia ser um "indício potencial" de uma análise que contestasse a noção difundida pela pós-modernidade de que não é possível uma identidade essencial, de que só existem identidades sociais múltiplas e de que a sociedade, portanto, constitui uma soma de identidades individuais.

Vale ressaltar aqui a contribuição de Wood $(1999$, p.18) a esse respeito, ao mostrar que

[...] os pós-modernistas rejeitam o universalismo iluminista alegando que ele nega a diversidade de experiências, culturas, valores e identidades humanas. Porém essa rejeição do universalismo em nome de um pluralismo libertador é contraditória e auto-anuladora. Um respeito sadio pela diferença e pela diversidade e pela pluralidade das lutas contra os vários tipos de opressão, não nos obriga a descartar todos os valores universalistas aos quais o marxismo, em sua melhor expressão, sempre esteve ligado, ou a abandonar a ideia de uma emancipação universal.

- A percepção, ainda que no âmbito das sensações, de que as mediações das novas tecnologias de ensino podem criar um novo tipo de subjetividade, não dominada pelos alunos, que instaura relações superficiais criando um sujeito inseguro, impedido de relações de historicidade perdendo qualquer senso ativo na História e transformando a aula em um espetáculo: "Concluíram que preferiam ter a professora de carne e osso e não de aço e óleo, porque é bom sentir o carinho e o calor humano da professora".

- Apesar de não ocorrer na experiência vivida, elementos que conduzissem à articulação entre o cotidiano e a História, algum indício de "preocupação" como o problema da História concreta dos sujeitos envolvidos na dramatização podem ser percebidos: "Qual seria a história de vida [...] concluíram que era uma mãe muito pobre, que não teve oportunidade de estudar, analfabeta". Mas esses elementos não foram trabalhados na aula, por meio do psicodrama pedagógico.

- Mesmo na experiência de dramatização vivida pelos alunos e professores de educação infantil, foi possível encontrar "indícios potenciais" de compreensão da realidade, quando buscaram refletir sobre "os desafios de suportar a pressão feita pelos colegas da turma a serem quem eles realmente são, sem que dessa forma fossem excluídos do grupo" ou, ainda, quando manifestaram a 
"preocupação" com a questão ontológica e gnosiológica: "Que ser humano queremos educar?"

- A indagação ao real como ponto de partida do processo de conhecimento também foi outro aspecto observado, denotando que existe a "preocupação" com a busca da compreensão da realidade: "quem pergunta tem o poder de conhecimento", mas, ao mesmo tempo, a expressão da dificuldade de romper com o senso comum: "A gente sempre acaba acreditando naquilo que os outros passam para a gente".

A partir da análise foi possível observar que os relatos representam momentos muito ricos como ponto de partida concreto para a compreensão da essência objetiva daquilo que é vivido no cotidiano. Porém, falta a dimensão da historicidade e as manifestações terminam por ficar presas nos limites do cotidiano, ou seja, no âmbito da "preocupação". E a "preocupação", como observa Kosik

[...] não é um estado psíquico ou um estado negativo do espírito, que se alterna com um outro, positivo [...] a "preocupação" é o enredamento do indivíduo no conjunto das relações que se the apresentam como mundo prático-utilitário. [...] A "preocupação" não é o estado de consciência cotidiano de um indivíduo cansado, que dela se pode libertar mediante a distração [...] o preocupar-se é o aspecto fenomênico do trabalho abstrato [...] onde o mundo humano se manifesta à consciência diária como um mundo já pronto e provido de aparelhos, equipamentos, relações e contatos, onde o movimento social do indivíduo se desenvolve como empreendimento, ocupação, onipresença, enleamento - em uma palavra, como "preocupação" (1976, p. 59-68 - grifos do autor).

A coisificação da práxis expressa pela "preocupação" significa que o homem é absorvido pelo mero ocupar-se utilitário, ou seja, só faz aquilo que considera que possa ter resultado imediato, dentro de uma perspectiva de ansiedade permanente para cumprir as metas e satisfazer suas necessidades imediatas. O homem tende a ficar retido no âmbito da necessidade, não conseguindo atingir o âmbito da liberdade. Não consegue com isso pensar na obra que faz como algo enraizado historicamente e se torna, por isto, alienado de sua ação, pois vê o que faz como um dado natural externo a sua ação de sujeito criador do mundo.

Como exemplo na educação, podemos citar a redução da relação pedagógica a temas do tipo: seguir a lógica escolar durante mais da metade da vida, ser aprovado para a série seguinte, obter êxito na atividade, a disciplina como um fim em si mesmo, eficiência, espontaneidade, cumprimento da tarefa proposta como um fim em si mesmo, fidelidade ao tempo programado e outros tantos que integram a cotidianidade escolar. A questão do conhecimento dessa realidade não é colocada como o 
cerne do processo de aprendizagem do homem no mundo, e a relação pedagógica se limita a lidar com aquilo que é familiar, fazendo os indivíduos se identificarem com esta realidade fragmentada e banalizada como sendo natural. E, enquanto se está no âmbito da "preocupação", é possível descrever e constatar a realidade, mas não a compreender e a explicar objetivamente, isto é, chegar a sua essência estrutural, as suas determinações históricas. Na medida em que o homem reflete sobre o sentido da cotidianidade, desperta nele a consciência do absurdo e ele passa, então, a não encontrar mais sentido na cotidianidade. Embora reconheça que o homem necessita historicamente executar cada vez mais automatismos para liberar tempo e espaço livres para as questões humanas, Kosik chama a atenção para o fato de que: "[...] o sentido do absurdo não surge da reflexão sobre o automatismo da cotidianidade, mas a reflexão sobre a cotidianidade é uma consequência da absurdidade em que a realidade histórica colocou o indivíduo" (1976, p. 76).

A superação da práxis familiarizada, coisificada e naturalizada se dá, portanto, pelo rompimento com a experiência cotidiana natural, pela desnaturalização da experiência cotidiana pelo processo de conhecimento da essência das coisas ou de suas determinações históricas. É evidente que esse processo não se realiza de uma só vez. No entanto, uma medida vai levando a outra, e gradativamente o sujeito consegue ir cada vez mais longe na destruição da pseudoconcreticidade. Esse é um processo que vai da tomada de consciência da alienação - daquilo que se faz no cotidiano-, passa pela modificação existencial e, ultrapassando este momento, caminha na direção de uma transformação revolucionária.

A modificação existencial que pode ser proporcionada pela vivência do psicodrama no processo pedagógico pode representar, portanto, um dos momentos de rompimento com o mundo da cotidianidade somente se for acompanhada da compreensão de que o sujeito é determinado por um sistema de relações objetivas, e de que a cotidianidade em que vive é produzida por ele em conjunto com os outros homens nas relações que se estabelecem objetivamente, sendo, portanto, um produto histórico. Contudo, a modificação existencial não se constitui, ainda, na transformação revolucionária do mundo.

A modificação existencial representa aquilo que já foi mencionado anteriormente, no diálogo com Kosik, como sendo o "drama individual de cada um no mundo", em que o indivíduo "não muda o mundo, mas muda somente a própria posição diante do mundo". Ao se elevar acima da cotidianidade, negando a experiência imediata como absurda, assumindo-se como alienado e ao mesmo tempo buscando uma vida autêntica, o sujeito corre o risco de, ao negar o mundo dos automatismos absurdos 
da realidade cotidiana, negar também a própria ação e ficar no imobilismo, não caminhando, desta maneira, para a transformação revolucionária que ocorre no plano da ação histórica.

\section{Algumas considerações finais sem caráter conclusivo, mas com forte apelo metodológico e histórico para a formação humana integral}

Apesar da identificação de alguns "indícios potenciais" de transformação das vivências em práxis transformadora pode ser constatado que as atividades proporcionadas pela aplicação da técnica didática em questão não proporcionaram condições de construção de um conhecimento que fosse significativo e revolucionário para os alunos. Eles permaneceram no âmbito da vivência e do senso comum e de um saber fragmentado.

No entanto, uma questão formulada por uma das professoras vale a pena ser retomada ao finalizar as presentes reflexões. Trata-se de uma das questões mais significativas para a educação: "Que ser humano queremos educar?". A origem desse problema bem como as tentativas de a ele responder não são, com toda certeza, um exercício meramente intelectual. Tem relação com a dialética do coletivo e do individual e com o modo pelo qual o conhecimento histórico é construído.

O pensamento é mediador da elaboração das respostas conceituais na medida em que realiza o movimento do singular ao particular e deste ao geral; e depois, do geral ao particular na forma de concreto pensado. Mas esse movimento histórico-dialético só ocorre se for alimentado de modo permanente pelas condições objetivas dadas pela realidade histórica.

Cardoso (2001), ao retomar as reflexões de Gramsci sobre a dialética do coletivo e do individual, considera que Gramsci é coerente ao dizer que a pergunta mais correta a ser formulada filosoficamente não seria 'o que é o homem,' mas 'o que pode o homem chegar a ser'?, ou seja, quais os limites em que podemos ser 'forjadores de nós mesmos'? Uma tal questão, para o autor, levaria a conceber o ser humano 'como uma série de relações ativas (um processo)'. Nisso, a 'individualidade tem a máxima importância', mas ocorre que a humanidade que se reflete em cada individualidade está composta de vários elementos: 1) o indivíduo; 2) os outros homens; 3) a natureza.

[...] A relação do indivíduo com os outros indivíduos e com a natureza é orgânica, não uma mera justaposição; e passa necessariamente pelo fato de pertencer a entidades transindividuais [...]. Se a individualidade própria é o conjunto destas relações, construir para si uma personalidade significa então adquirir consciência de tais relações; e modificar a personalidade significa 
modificar o conjunto destas relações (CARDOSO, 2001, p. 78-79).

Complementando as observações realizadas por Cardoso (2001) fica aqui o desafio para todos nós educadores que pensam a educação tendo como princípio o conceito de trabalho educativo desenvolvido por Saviani (1991, p. 14) em “Pedagogia Histórico-crítica: primeiras aproximações”: “[...] o trabalho educativo é o ato de produzir, direta e intencionalmente, em cada indivíduo singular, a humanidade que é, produzida histórica e coletivamente pelo conjunto dos homens".

\section{Referências}

CARDOSO, C. F. Epistemologia pós-moderna: a visão de um historiador. In: FRIGOTTO, G.; CIAVATTA, M. (Orgs.), Teoria e educação no labirinto do capital. Petrópolis: Vozes, 2001. p. 75-90.

DUARTE, N. Conhecimento tácito e conhecimento escolar na formação do professor (Por que Donald Schön não entendeu Luria). Educação e Sociedade, Campinas, v. 24, n. 83, p. 601-625, 2003.

FRIGOTTO, G. A nova hegemonia da burguesia no Brasil dos anos 90 e os desafios de uma alternativa democrática. In: FRIGOTTO, G.; CIAVATTA, M. (Orgs.), Teoria e Educação no labirinto do capital. Petrópolis: Vozes, 2001. p. 21-46.

KOSIK, K. Dialética do concreto. Tradução Célia Neves e Alderico Toríbio. 2. ed. Rio de Janeiro: Paz e Terra, 1976.

LEFEBVRE, H. A reprodução das relações de produção. Porto: Publicações Escorpião, 1973.

MARX, K. El capital. México: Fondo de Cultura Económica, tomo III, 1959.

MARX, Posfácio da segunda edição. O capital - crítica da economia política. Tradução Reginaldo Sant'Ana. Livro 1. Rio de Janeiro: Civilização Brasileira, 2008.

MARX, K.; ENGELS, F. A ideologia alemã. EPU, Montevidéu, 1959a.

. Textos sobre educação e ensino. São Paulo: Moraes, 1959b.

MATTOS, F. Anatomia do riso - Quentin Skinner discute o significado do fenômeno desde a Antiguidade (sobre a obra Hobbes e a Teoria do Riso). Folha de S.Paulo, Jornal de Resenhas, 11 jan. p. 3, 2003.

MORIN, E. Os sete saberes necessários à educação do futuro. Tradução Catarina Eleonora F. da Silva e Jeanne Sawaya. 6. ed. São Paulo: Cortez; Brasília: Unesco, 2002.

NORONHA, O. M. Pesquisa participante: repondo questões teórico-metodológicas. In: FAZENDA, I. (Org.), Metodologia da pesquisa educacional. 2. ed. aumentada. São Paulo: Cortez, 1991. p. 139-143.

Políticas neoliberais, conhecimento e educação. Campinas: Alínea, 2002.

. A práxis como categoria central para o entendimento da educação sócio-comunitária. Revista Ciências da Educação, Ano VII, n. 14, p. 59-130, 2006.

SAVIANI, D. Pedagogia Histórico-crítica: primeiras aproximações. São Paulo: Cortez: Autores Associados, 1991. (Coleção polêmicas do nosso tempo; v. 40) 
STABILE, C. A. Pós-modernismo, feminismo e Marx: notas do abismo. In: WOOD, E. M.; FOSTER, J. B. (Orgs), Em defesa da história: marxismo e pós-modernismo. Tradução Ruy Jungman. Rio de Janeiro: Jorge Zahar, 1999. p. 145-160.

VÁZQUEZ, A. S. Filosofia da práxis. Tradução Luiz Fernando Cardoso. 2. ed. Rio de Janeiro: Paz e Terra, 1977.

WOOD, E. M. O que é a agenda "pós-moderna"? In: WOOD, E. M.; FOSTER, J. B. (Orgs.), Em defesa da história: marxismo e pós-modernismo. Tradução Ruy Jungman. Rio de Janeiro: Jorge Zahar, 1999. p. 722.

Recebido em: 28/08/2017

Aceito em: 18/10/2017 